\title{
Isolation and Molecular Characterization of Termite GUT Microflora
}

\author{
Vishal Devaraj $^{1^{*}}$, Sheetal S Kesti ${ }^{2}$ \\ ${ }^{1,2}$ Dept. of Studies in Biotechnology and Microbiology, Karnatak University, Dharwad \\ Corresponding author: vishaldevaraj90@gmail.com, Tel.: +919902342890
}

Available online at: www.isroset.org

Received: 26/Apr/2019, Accepted: 05/Jun/2019, Online: 30/Jun/2019

\begin{abstract}
As termite is a social insect, its colony consists of three castes. i.e. reproductive, worker \& soldier castes. In their role of cellulose digestion, the worker termite uses two sources of cellulolytic enzyme that include cellulases produced by the termite and the gut symbionts. Odontotermes obesus classified in mound builder termite, mostly depend on cellulolytic bacteria for cellulose digestion. This study aims to characterize cellulolytic bacteria of termite gut symbionts of worker Odontotermes obesus and to identify cellulolytic bacteria based on sequences of $16 \mathrm{~S}$ ribosomal RNA(rRNA) gene. Cellulolytic bacteria of termite gut were isolated and cultured in CMC media. Gram's staining and biochemical characteristics were analysed. The two bacterial isolates were selected from Odontotermes obesus with aerobic conditions for the analysis of 16S rRNA gene sequences. BLAST-N result of 16S rRNA gene sequences of white and yellow colony isolates showed that the isolate has highest similarity with Trabulsiella odontotermitis and Chryseobacterium ureilyticum, respectively.
\end{abstract}

Keywords: Carboxymethylcellulose, 16S rRNA, Gut bacteria, Odontotermes obesus, Trabulsiella odontotermitis, Chryseobacterium ureilyticum

\section{INTRODUCTION}

Termites play a great role in terrestrial ecosystem by recycling lignocellulosic biomass, which refers to a mixture of cellulose, hemicellulose and lignin. Termites come in class insecta, order Blattodea and infraorder as isoptere. Termites are one of the most important soil insects that efficiently decompose lignocelluloses with the aid of their associated microbial symbionts to simpler form of sugars, which later fermented to ethanol using yeast organism. Termites are said to dissimilate a significant proportion of cellulose (74-99\%) and hemicellulose (65-87\%) components of lignocellulose they ingest [1]. Termites are successful wood-degrading organisms distributed all over the world, which are important for carbon turnover in the environment and they are potential sources of biochemical catalysts [2][3][4][5]. These termites form symbiotic association with different microorganisms in its own gut, which as a result of evolution and modification, makes the termites able to degrade the lignocelluloses in their diets, as well as it also improves their immunity, reproduction, and other physiological functions [4][6][7][8]. Termites are called as social insects that have various morphologies. Termites based on their reproduction capacity, are classified into two main types such as reproductive (queen) and nonreproductive (worker and soldier castes). Queen's main job is to produce and lay eggs, soldier's job is to guard and protect the colony, and worker's job is to nurse, repair the colony, and collection of food [9].
Termite consists of a complex association of different species, divided into higher and lower termites. Lower termites shelter a dense population of prokaryote and protists (single celled eukaryotes) in their gut. Higher termites consist only one apical family (Termitidae) but more than three quarters of all termite species. While they also shelter a dense and diverse array of prokaryotes, higher termites do not contain protists [1]. This association of gut cellulolytic protists with lower termites is a well-known example of mutual symbiosis. The protists endocytose wood or cellulose particles which produces acetate, which is then further absorbed by termites as carbon and energy sources [1].

Cellulose Decomposition Systems: Endogenous cellulase of termite origin ( $\beta$-glucosidase and endo- $\beta$-1,4-glucanase) which are excreted from the salivary glands or the gut have been identified and characterized in both higher and lower termites. Molecular analysis tells that these endogenous enzymes are members of the glycosyl hydrolase family 9 (GHF9). In higher termites the endogenous cellulolytic activity meets the metabolic requirement. In lower termites, the cellulolytic activity is found in the hindgut. Thus, the ingested cellulose can be moderately degraded by the endoglucanase of termite origin, then the cellulose which is not hydrolysed travels to the hind gut, where it can be endocytosed and is fermented by the symbiotic protists in lower termites. Termites grind and crunch the ingested material [1]. 
Microbial ecology of the Gut Symbiotic Systems: In the final process of degradation microbes consume electron equivalents, usually a molecular hydrogen, which is produced from the intermediate steps. Efficient elimination of the electron equivalents greatly enhances the decomposition by itself. In the gut, microbial fermentation of termites, $\mathrm{CO}_{2}$ reducing acetogenesis as an " $\mathrm{H}_{2}$ sink" reaction is the most distinguishing and enigmatic features due to thermodynamic deficiency of acetogenesis, Methanogens usually dominate when there is a reduced supply of oxygen. Although methanogenesis is very much common in the gut of termites, acetogenesis dominates methanogenesis, particularly in wood-eating termites. The acetate which is produced by the gut microbiota support up to $100 \%$ of the respiratory requirement of termites. Nitrogen distribution affects the efficient decomposition of lignocelluloses indirectly but significantly. Nitrogen fixation by the gut symbionts is the crucial aspects of termite symbiotic system, since the diet of termites is usually low in nitrogen sources. The gut symbionts also play a role in degradation of disposed nitrogen waste such as uric acid which is produced during the metabolism of termites [1]. The protists or the protozoans which are able to engulf and metabolize cellulose into acetate, hydrogen and carbondioxide. Then the bacteria utilize the $\mathrm{H}_{2}$ and $\mathrm{CO}_{2}$ to form additional acetate. There are also some methanogens present which can use the $\mathrm{H}_{2}$ and $\mathrm{CO}_{2}$ to form methane through inter species hydrogen transfer to remove excess hydrogen, which can be toxic to microorganisms at higher concentrations.

Cellulolytic Bacteria and Biotechnology: In recent years, the gas price is increasing and environmental concerns have become the driving force for developing different energy sources, particularly fuel such as ethanol for automobiles. Currently, corn has become the primary raw material for the ethanol production in the United States. However, lignocellulosic biomass has the potential to provide a more economical feedstock as it is widely available, production and low starting value. Conversion of lignocelluloses to ethanol employs five steps:

1) Isolation of potent microbe from the termite's gut.

2) Pre-treatment is done to breakdown lignin and open the crystalline structure of cellulose.

3) Inoculation of the pre- treated cellulolytic biomass by microbes present in the termite's gut.

4) Treatment with the enzymes synthesized by bacteria in termite's gut to release simple sugar.

5) Microbial fermentation of simple sugar to ethanol is done using yeast organism.

However, typical physical and chemical pre-treatments require high-energy (steam or electricity) as well as corrosion-resistant and high-pressure reactors, which indirectly increases the cost of pre-treatment and need for specialty equipment. Further, chemical pre-treatments can cause damage to subsequent enzymatic hydrolysis and microbial fermentation apart from producing acidic or alkaline waste water which requires pre-disposal treatment to ensure environmental safety [10]. Microbial pre-treatment requires microorganisms and their enzyme systems to breakdown lignin which is present in lignocellulosic biomass. This environment friendly approach has recently received increased attention and has potential advantages over the prevailing physio-chemical pre-treatment technologies due to reduced energy and material costs, simplified processes and equipment, and use of the biologically based catalysts [11].

\section{MATERIALS AND METHODS}

Collection of termites: Around 30 to 40 worker termites were collected from termite mounds of Karnataka University Dharwad main campus.

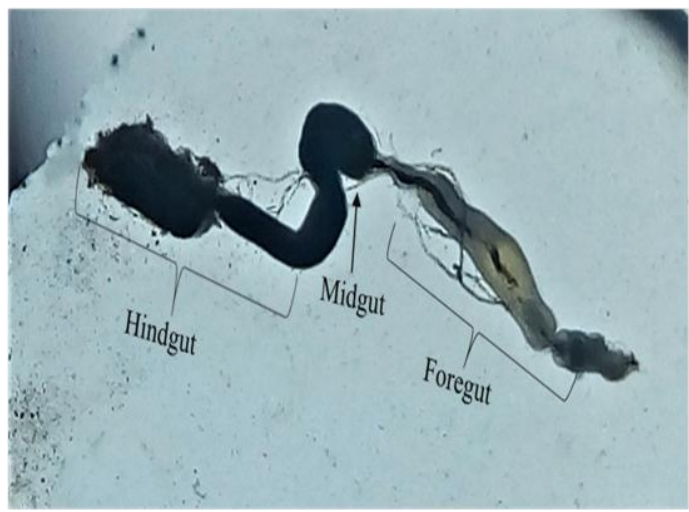

Figure 1: Entire gut compartments sampled from termite Odontotermes obesus.

Isolation of termite gut: The termites were surface sterilized by sterile water followed by $95 \%$ ethanol and the gut from each termite was dissected out using fine forceps and immersed in $0.9 \%$ sterile saline water. About 30 guts from the worker termites were dissected. The tube containing $1 \mathrm{ml}$ of $0.9 \%$ saline and guts was briefly vortexed and left to stand for 15 minutes. After the gut tissue was settled down, the supernatant was used as a microbial inoculum

Culturing of organisms: The whole supernatant was used as a microbial inoculum, the entire inoculum of $100 \& 50 \mu 1$ was used and is spread on Nutrient Agar media with the composition of $0.5 \mathrm{~g}$ peptone, $0.3 \mathrm{~g}$ beef extract, $0.5 \mathrm{~g} \mathrm{NaCl}$, $1.5 \mathrm{~g}$ agar and $1 \mathrm{~g}$ of carboxymethylcellulose. Plates were incubated at $37^{\circ} \mathrm{C}$ for $24 \mathrm{hrs}$ (Figure 2). 


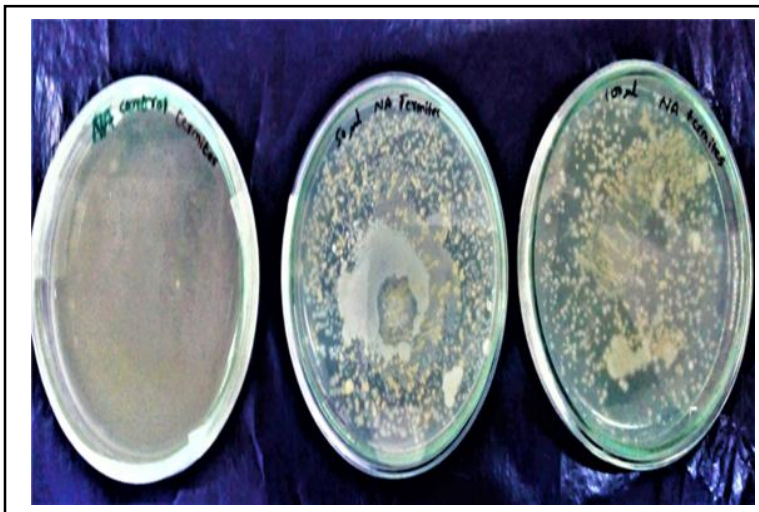

(Figure 2): (A) No sample inoculated in control. (B) $50 \mu \mathrm{l}$ sample inoculated (C) $100 \mu \mathrm{l}$
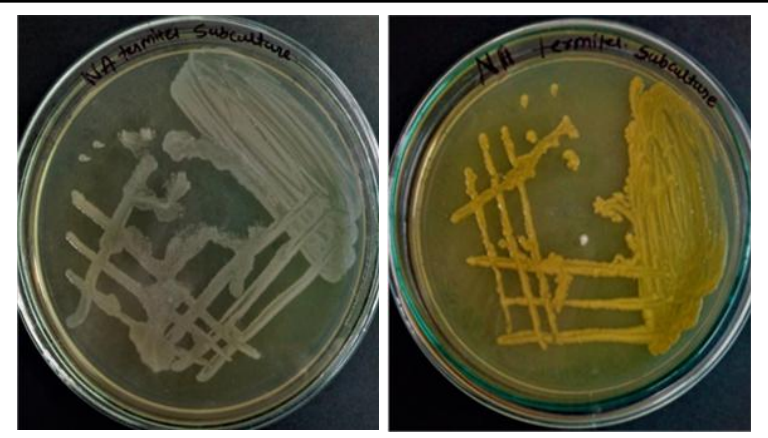

(Figure 3): (A) White colony selected for subculture. (B) Yellow colony selected for subculture

Subculture of growth: After one day of incubation yellow and white colony were selected for subculture. Different nutrient agar media were prepared with $1 \% \mathrm{CMC}$ were prepared and autoclaved. This media is poured into the plate after solidifies the yellow and white colony were streaked on the plates and kept for incubation in inverted position for 24 hours at $37^{\circ} \mathrm{C}$ (Figure 3 ).

Colony characterization: After 24hrs of incubation, the colony morphology was studied. Colony morphology is a method which is used to describe the characteristics of individual colony growing on agar in a Petri dish. The yellow and white colony were taken in that colour, form, elevation, margin and opacity were studied.

Pure culture: Pure culture, in microbiology, a laboratory culture containing a single species of organisms. A pure culture is usually derived from a mixed culture by transferring small sample into new, sterile growth medium in such a manner as to disperse the individual cells across the medium surface or by thinning the simple many fold before inoculating in new medium, each will form a discrete colony, which may then be used to inoculate more medium, with the assurance that only one type of organisms will be present.

Gram's Staining for differentiation of bacteria: This is the most important differential technique used in bacteriology. There are two groups, gram positive and gramnegative bacteria. The gram stain, developed in 1884 by Danish physician Hans Christian Gram. It is a differential staining procedure because it divides bacteria into two classes Gram positive and Gram negative.

Gram staining differentiates bacteria by the chemical and physical properties of their cell walls by detecting peptidoglycan, which is present in the cell wall of grampositive bacteria. Gram-negative cells also contain peptidoglycan, but a very small layer of it which is dissolved when the alcohol is added. This is why the cells loses its initial colour from the primary stain. The gram-positive bacteria retain the crystal violet dye, and thus are stained violet, while the gram-negative bacteria don't; after washing, a counter stain is added (safranin) that will stain these gramnegative bacteria a pink colour. Both gram-positive and gram-negative bacteria pick up the counterstain. The counterstain, however, is unseen on gram-positive bacteria because of the darker crystal stain.

Biochemical Tests: Biochemical tests are used for the identification of bacteria species based on the differences in the biochemical activities of different bacteria.

Glucose Fermentation test: When microorganisms ferment glucose, an acid or acid with gas are produced. Common end-products of bacterial fermentation include lactic acid, formic acid, acetic acid, butyric acid, butyl alcohol, acetone, ethyl alcohol, carbon-dioxide and hydrogen.

The nutrient broth was prepared with the composition of $0.5 \mathrm{~g}$ peptone, $0.3 \mathrm{~g}$ beef extract, $0.5 \mathrm{~g} \mathrm{NaCl}$ in $100 \mathrm{ml}$ of distilled water, then the broth was sterilized. Then the broth was taken into the test tube and the two bacterial isolated were aseptically inoculated. The Durham tube were filled with the same bacterial isolates and inserted upside down into the test tube to detect gas production. The tubes were incubated at $37^{\circ} \mathrm{C}$ for $48 \mathrm{hrs}$.

Catalase test: The enzyme catalase mediates the breakdown of hydrogen peroxide into oxygen and water. The presence of the enzyme in a bacterial isolate is evident when a small inoculum is introduced into hydrogen peroxide, and the rapid elaboration of oxygen bubbles occurs. The lack of catalase is evident by a lack of or weak bubble production. The culture should not be more than 24 hours old. Bacteria thereby protect themselves from the lethal effect of Hydrogen peroxide which is accumulated as an end product of aerobic carbohydrate metabolism. 
The nutrient broth was aseptically inoculated with the two bacterial isolates then incubated at $37^{\circ} \mathrm{C}$ for $24 \mathrm{hrs}$. The broth was taken into the test tube then 2 to 3 drops of $3 \%$ hydrogen peroxide solution is added to observe the effervescence.

Indole Production Test: Tryptophan is an essential amino acid is oxidised but some bacteria by the enzyme tryptophanase resulting the formation of indole, pyruvic acid and ammonia. The indole test is performed in tryptophan broth and the production of indole in the reaction is detected by adding Kovac's reagent, this reacts with indole to produce a red coloured compound.

Tryptophan broth was taken into the test tube then inoculated with the two bacterial isolates which was incubated at $37^{\circ} \mathrm{C}$ for $48 \mathrm{hrs}$. After $48 \mathrm{hrs}$ of incubation $1 \mathrm{ml}$ of Kovac's reagent was added.

Methyl Red and Voges Proskauer (MRVP) Test: MR and VP Tests is used to differentiate two major types of facultative anaerobes that produces large amount of acids and those that produce neutral product acetone as end product both are similar because they physiological related and are performed on a same media MRVP broth. Results are obtained by adding methyl red for MR and VP reagent 1 and 2 for VP test.

The Methyl red and Voges-Proskauer broth was prepared with the composition of $0.7 \mathrm{~g}$ of peptone, $0.5 \mathrm{~g}$ of glucose, $0.5 \mathrm{~g}$ of dipotassium phosphate in $100 \mathrm{ml}$ of distilled water with $\mathrm{pH} 6.9$ was prepared and aseptically inoculated with the two bacterial isolates and inoculated at $37^{\circ} \mathrm{C}$ for $48 \mathrm{hrs}$.

For Methyl Red test, after $48 \mathrm{hrs}$ of incubation, aliquot $3 \mathrm{ml}$ of the broth to a clean test tube. Then 5 drops of Methyl red reagent were added to observe the medium for the immediate development of a red colour.

For Voges-Proskauer test, after 48hrs of incubation, the broth was taken into the test tube then 6 drops of 5\% alphanaphthol and next $40 \% \mathrm{KOH}$ were added. The tubes were mixed well to aerate and allowed to remain undisturbed for 5 minutes to observe the pink-colour development

\section{Amplification and Identification of Bacterial Isolates By 16s r-RNA Sequence Analysis: \\ For White Colony and Yellow Colony:}

1. DNA was isolated from the culture -White colony. Quality was evaluated on 1.2\% Agarose Gel; a single band of high-molecular weight DNA has been observed. Isolated DNA was amplified with $16 \mathrm{~S}$ rRNA Specific Primer (8Fand 1492R) using Veriti ${ }^{\circledR} 96$ well Thermal Cycler (Model No. 9902). A single discrete PCR amplicon band of $1500 \mathrm{bp}$ was observed (Figure $1 \& 2$ ). The PCR amplicon was enzymatically purified and further subjected to Sanger Sequencing. Bi-directional DNA sequencing reaction of PCR amplicon was carried out with 704F and 907R primers using BDT v3.1 Cycle sequencing kit on ABI 3730xl Genetic Analyzer. Consensus sequence of $1500 \mathrm{bp}$ for White colony and 1437bp for Yellow colony 16S rDNA was generated from forward and reverse sequence data using aligner software.

Bioinformatics Analysis of White \& Yellow Colony: The $16 \mathrm{~S}$ rDNA sequence was used to carry out BLAST alignment search tool of NCBI GenBank database. Based on maximum identity score first Fifteen sequences were selected and aligned using multiple alignment software program ClustalW. Distance matrix was generated using RDP database and the Phylogenetic tree was constructed using MEGA6.

\section{RESULTS}

Colony characterization and Gram's staining: Colony morphology of white and yellow colony is displayed in [Table 1]. Gram staining results showed Gram negative bacilli in both the isolates. [Figure 4]

Glucose Fermentation Test: Gas production were observed in both the Durham tubes. The nutrient broth were inoculated with yellow and white colony culture. According to Bergey's manual Vibrio species or Aeromonas species may be present. [Figure 5, (A)]

Catalase Test: Catalase test showed the positive result; the air bubbles were produced in both the tubes containing yellow and white colony. Micrococcus species or Staphylococcus species May be present. [Figure 5, (B)]

Indole Production Test: A bright red colour ring was observed in both yellow and white colony tubes. The pink colour ring indicates the presence of indole. Citrobacter diversus, Escherichia coli, Erwinia chrysanthemi, Klebsiella oxytoca may be present. [Figure 5, (C)].

Methyl Red Test: Methyl red test showed the positive result, changing the colour to red by adding methyl red indicator in both yellow and white colony test tubes. Enterobacter intermedius may be present. [Figure 5, (D)]

Voges-Proskauer Test: There were no colour change observed in Voges-Proskauer test. Citrobactor freundii, Serratia fontocola, Klebsialla pneumoniae may be present. [Figure 5, (E)] 
Table 1: Colony characterization

\begin{tabular}{|l|l|l|l|l|l|l|}
\hline Sample & Colour & Form & Elevation & Margin & Opacity & Gram's Reaction \\
\hline Colony- 1 & White & Irregular & Crateriform & Entire & Opaque & Gram negative bacilli \\
\hline Colony- 2 & Yellow & Irregular & Crateriform & Entire & Opaque & Gram negative bacilli \\
\hline
\end{tabular}

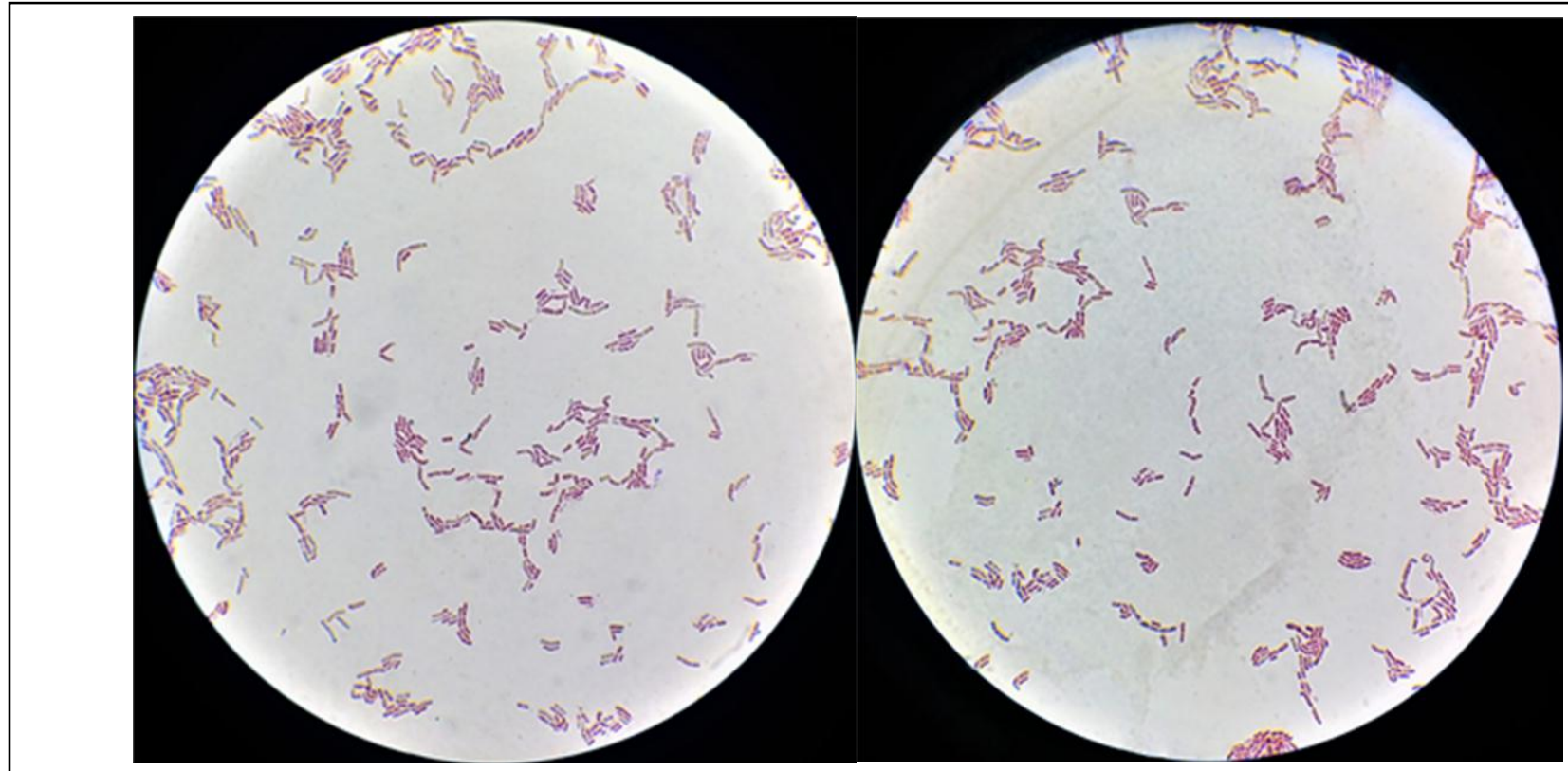

Figure 4:100x oil immersion of A) White colony B) Yellow colony, which is Gram negative bacilli

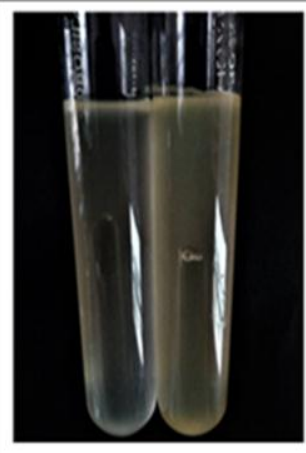

Glucose fermentation test: formation of gas bubbles in the Durham tubes, therefore positive result was observed.

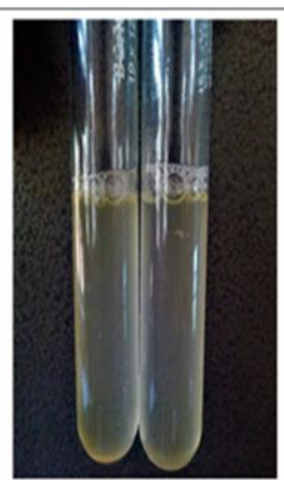

Catalase Test: Air bubbles was observed in both the test tubes (yellow and white colony),

therefore positive result was observed.

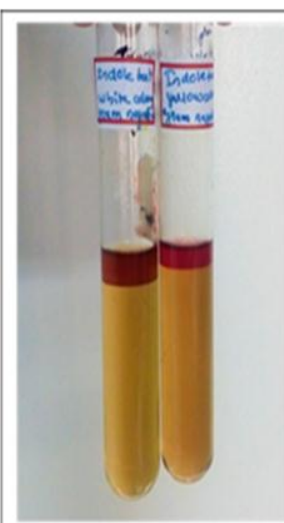

Indole Test: The red coloured ring was observed in the surface of al cohol layer of the broth.

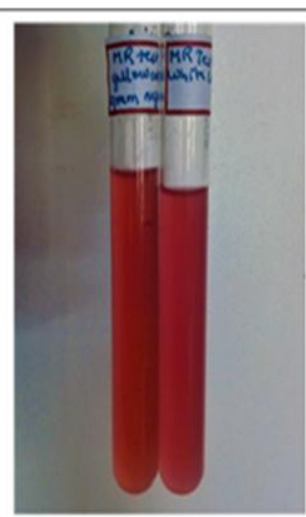

Methyl red test: The colour of the broth changes to red colour, which indicates the positive result.

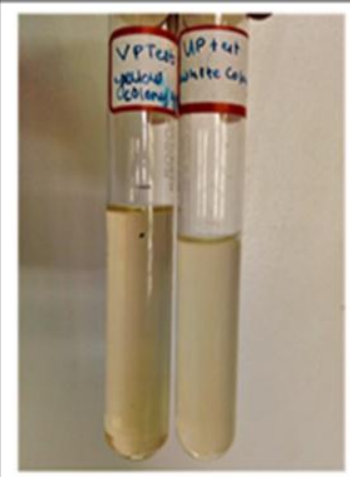

Voges-Proskauer Test: There is no change in colour in bacterial broth, therefore this test is negative.

Figure 5: Biochemical test results of White and Yellow colony: (A)Glucose fermentation test, (B)Catalase test, (C)Indole test, (D)Methyl red test, (E)Voges-Proskauer test. 


\section{Identification of Cellulolytic Bacteria Through PCR Amplification of The 16s rDNA:}

DNA extraction, PCR amplification and purification of PCR product was executed in laboratory using standard guidelines to avoid cross contamination. Samples were sequenced and nucleotide blast search was performed with partial sequences of the $16 \mathrm{~S}$ rDNA.

The 16s rRNA gene is a component of 30s ribosomal subunit of prokaryotes, commonly used in molecular characterization and determination of phylogenetic tree A) White colony \& B) yellow colony.
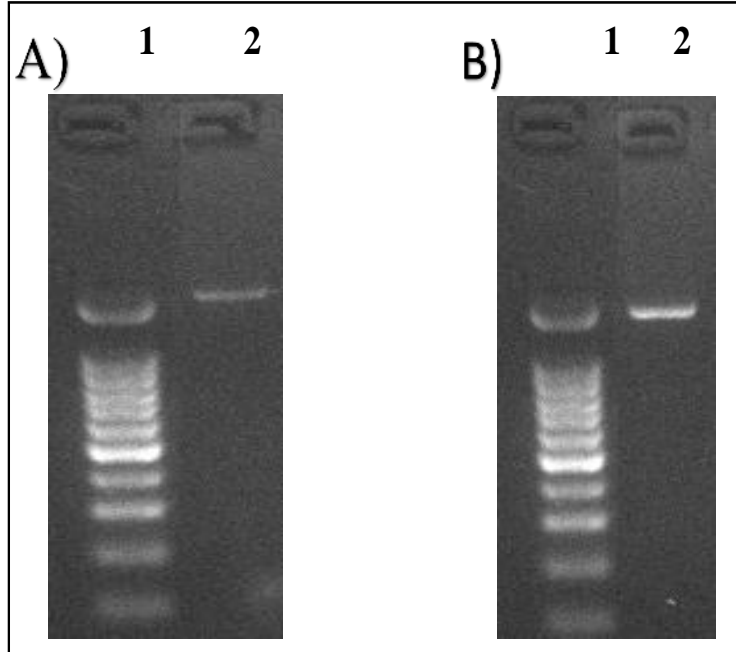

1.2\% Agarose gel showing single $1500 \mathrm{bp}$ of $16 \mathrm{~S}$ rDNA amplicon. Lane 1: 100bp DNA ladder; Lane 2: 165 rDNA amplicon among prokaryotes. The contig region of 16s rRNA gene from white colony was $1500 \mathrm{bp}$ and yellow colony was 1437bp. Comparing these contig regions with NCBI GeneBank entries using BLAST algorithm showed that white colony has $99.24 \%$ similarity with Trabulsiella odontotermitis strain Eant 3-9 and Yellow colony showed 98.61\% similarity with Chryseobacterium ureilyticum strain F-Fue-04IIIaaaa. these are based on nucleotide homology a Phylogenetic analysis. (Table 2 and 3)

Quality check on 1.2\% Agarose gel for

\section{Evolutionary Relationship for White \& Yellow Colony isolates:}

The evolutionary history was inferred using the NeighborJoining method [11]. The bootstrap consensus tree inferred from 1000 replicates [12] is taken to represent the evolutionary history of the taxa analysed [12]. Branches corresponding to partitions reproduced in less than 50\% bootstrap replicates are collapsed. The evolutionary distances were computed using the Maximum Composite Likelihood method [13] and are in the units of the number of base substitutions per site. The analysis involved 16 nucleotide sequences. Codon positions included were $1 \mathrm{st}+2 \mathrm{nd}+3 \mathrm{rd}+$ Noncoding. All positions containing gaps and missing data were eliminated. There were a total of 1371 positions in the final dataset of white colony and Yellow colony has 1431 positions in final dataset. Evolutionary analyses were conducted in MEGA6 [14]. Phylogenetic analysis tree for White colony \& Yellow colony is represented in Figure 6.

Table 2: Blast Data of 16s rRNA gene of White Colony:

\begin{tabular}{|l|l|l|l|l|l|l|}
\hline Accession & Description & $\frac{\text { Max }}{\text { score }}$ & $\frac{\text { Total }}{\text { score }}$ & $\frac{l}{\text { Query }}$ \\
coverage & E value & Max ident \\
\hline NR_043860.1 & Trabulsiella odontotermitis strain Eant 3-9 & 2595 & 2595 & $95 \%$ & 0.0 & $99.24 \%$ \\
\hline NR_114235.1 & Trabulsiella guamensis strain NBRC 103172 & 2551 & 2551 & $97 \%$ & 0.0 & $98.09 \%$ \\
\hline NR_104890.1 & Citrobacter koseri strain CDC-8132-86 & 2503 & 2503 & $97 \%$ & 0.0 & $97.41 \%$ \\
\hline NR_118105.1 & Citrobacter koseri strain LMG 5519 & 2501 & 2501 & $97 \%$ & 0.0 & $97.34 \%$ \\
\hline NR_118588.1 & Citrobacter koseri strain CIP 82.87 & 2490 & 2490 & $97 \%$ & 0.0 & $97.46 \%$ \\
\hline NR_074910.1 & Salmonella enterica subsp. enterica strain LT2 & 2488 & 2488 & $98 \%$ & 0.0 & $96.97 \%$ \\
\hline NR_104709.1 & Salmonella enterica subsp. enterica strain LT2 & 2479 & 2479 & $97 \%$ & 0.0 & $97.14 \%$ \\
\hline NR_074799.1 & Salmonella enterica subsp. enterica strain Ty2 & 2473 & 2473 & $99 \%$ & 0.0 & $96.71 \%$ \\
\hline NR_112011.1 & Raoultella planticola ATCC 33531 strain JCM 7251 & 2473 & 2473 & $96 \%$ & 0.0 & $97.38 \%$ \\
\hline NR_119108.1 & Salmonella enterica subsp. enterica serovar Typhimurium & 2466 & 2466 & $99 \%$ & 0.0 & $96.51 \%$ \\
\hline
\end{tabular}




\begin{tabular}{|l|l|l|l|l|l|l|}
\hline Accession & Description & Max & Total & Query & E value & Max ident \\
\hline & strain ATCC 13311 & $\underline{\text { score }}$ & $\underline{\underline{\text { score }}}$ & & $\underline{\text { coverage }}$ & $\underline{ }$ \\
\hline
\end{tabular}

Table 3: Blast Data of 16s rRNA gene of Yellow Colony:

\begin{tabular}{|l|l|l|l|l|l|l|}
\hline Accession & Description & $\begin{array}{l}\text { Max } \\
\text { score }\end{array}$ & $\begin{array}{l}\text { Total } \\
\text { score }\end{array}$ & $\begin{array}{l}\text { Query } \\
\text { coverage }\end{array}$ & E value & Max ident \\
\hline KY270506.1 & Chryseobacterium sp. E1771 & 2543 & 2543 & $100 \%$ & 0.0 & $98.61 \%$ \\
\hline KY270505.1 & Chryseobacterium sp. E1671 & 2543 & 2543 & $100 \%$ & 0.0 & $98.61 \%$ \\
\hline KY270504.1 & Chryseobacterium sp. E1571 & 2540 & 2540 & $99 \%$ & 0.0 & $98.61 \%$ \\
\hline KY117480.1 & Chryseobacterium sp. strain E1571 & 2540 & 2540 & $99 \%$ & 0.0 & $98.61 \%$ \\
\hline MH628236.1 & Chryseobacterium indologenes strain FC2955 & 2536 & 2536 & $100 \%$ & 0.0 & $98.54 \%$ \\
\hline LN681561.1 & Chryseobacterium indolo, type strain DSM 16777T & 2536 & 2536 & $100 \%$ & 0.0 & $98.54 \%$ \\
\hline JQ433943.1 & Chryseobacterium sp. VT1 & 2536 & 2536 & $100 \%$ & 0.0 & $98.54 \%$ \\
\hline HQ895718.1 & Chryseobacterium sp. TFB & 2536 & 2536 & $100 \%$ & 0.0 & $98.54 \%$ \\
\hline NR_042503.1 & Chryseobacterium ureilyticum strain F-Fue-04IIIaaaa & 2536 & 2536 & $100 \%$ & 0.0 & $98.54 \%$ \\
\hline JX035956.1 & Chryseobacterium jejuense strain JDG189 & 2531 & 2531 & $100 \%$ & 0.0 & $98.47 \%$ \\
\hline
\end{tabular}

\section{Phylogenetic Analysis Tree For A) White colony \& B) yellow colony:}
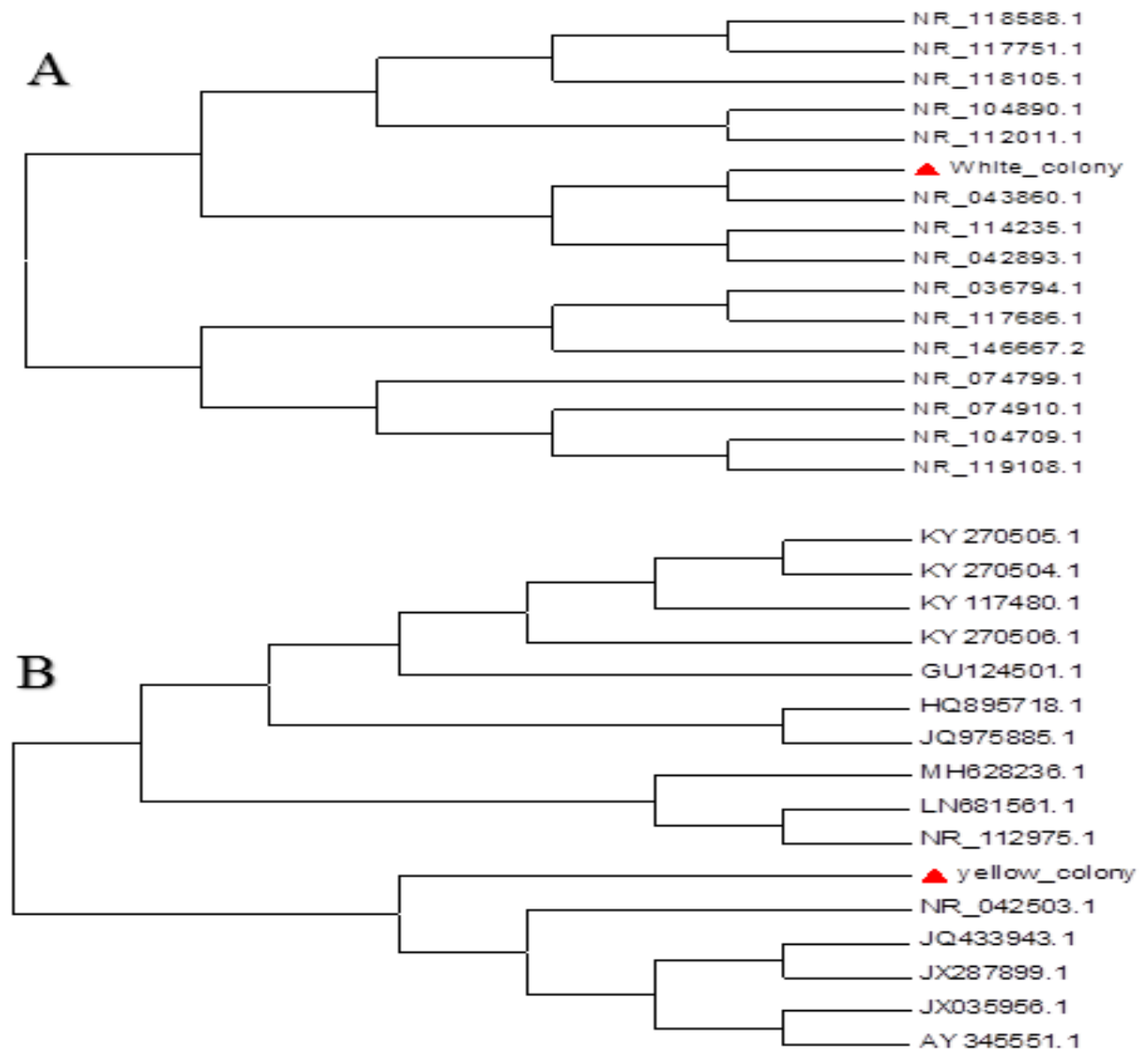

Figure 6: Phylogenetic analysis tree for White colony \& Yellow colony 


\section{DISCUSSION}

Bacteria isolated from the termite gut have characteristics of either facultative anaerobe or microaerophile (Wenzel etal.,2002). Based on Gram's staining white and yellow colony isolates are gram negative bacteria. Biochemical analysis i.e. Glucose fermentation test, Catalase test, Indole test, Methyl red test, Voges-Proskauer tests were performed the two bacterial isolates were selected to identify cellulolytic activity based on sequences of $16 \mathrm{~S}$ ribosomal RNA (rRNA) gene.

The amplification of 16S rRNA gene sequences with primer $704 \mathrm{~F}$ and $907 \mathrm{R}$ showed $1500 \mathrm{bp}$ for white colony isolate and for yellow colony isolate showed 1437bp DNA amplicons. Based on molecular identification of 16S rRNA gene, White colony has $99.24 \%$ similarity with Trabulsiella odontotermitis strain Eant 3-9 and Yellow colony showed 98.61\% similarity with Chryseobacterium ureilyticum strain F-Fue-04IIIaaaa. Trabulsiella odontotermitis and Chryseobacterium ureilyticum are gram negative bacterium with bacilli-cell shape, and has positive reaction for biochemical assay of glucose fermentation test, catalase test, indole test, methyl red test and showed negative reaction for Voges-Proskauer tests.

Trabulsiella odontotermitis is gram negative, Facultatively anaerobic, biochemical analysis has a positive reaction with catalase test and glucose fermentation test and has negative reaction with indole test. The type of strain Trabulsiella odontotermitis were isolated from the gut of the termite Odontotermes formosanus Shiraki from southern Taiwan [15]. However, in this study White colony isolate, Trabulsiella odontotermitis is Gram negative, aerobic \& showed positive reaaction with catalase test, glucose fermentation test and Indole test. This Trabulsiella odontotermitis strain was isolated from worker Odontotermes obesus from Karnatak University Dharwad main campus.

Chryseobacterium ureilyticum is gram negative, aerobic, biochemical analysis has positive reaction with catalase test, indole test and glucose fermentation test. Grows at $25^{\circ} \mathrm{C}$ but not at $37^{\circ} \mathrm{C}$. Grows on plain nutrient agar and on nutrient agar containing up to $2 \% \mathrm{NaCl}$, but not on nutrient agar containing $3 \% \mathrm{NaCl}$. The strain, Chryseobacterium ureilyticum was isolated from a steel surface of a beerbottling plant in Germany [16]. In this study Yellow colony, Chryseobacterium ureilyticum is gram negative, aerobic, biochemical analysis showed positive reactions with catalase test, indole test and glucose fermentation test. Grows at $37^{\circ} \mathrm{C}$ and Nutrient media contains $1 \%$ Carboxymethylcellulose with $0.5 \mathrm{~g} \mathrm{NaCl}$. This Chryseobacterium ureilyticum strain was isolated from worker Odontotermes obesus from Karnatak University Dharwad main campus. The difference in many of these characteristics indicate the white and yellow colony, Trabulsiella odontotermitis \& Chryseobacterium ureilyticum strains are unique.

\section{CONCLUSION}

In this study, the worker termite i,e Odontotermes obesus were collected, then the microorganisms were isolated from the gut which were cultured. The White and Yellow colony were selected for subculture and gram's staining result showed Gram Negative Bacilli for both the isolates. Biochemical analysis was performed which both the isolates showed positive result with Glucose fermentation test, Catalase test, Indole test, Methyl red test and showed negative result for Voges-Proskauer test. Molecular analysis of 16s rRNA showed that white colony has highest similarity with Trabulsiella odontotermitis and yellow colony showed highest similarity with Chryseobacterium ureilyticum were found in gut, which were found unique. The molecular studies on cellulolytic activities of termites and their gut microorganisms will be carried out in future.

\section{ACKNOWLEDGMENTS}

Authors would like to thank the Department of Biotechnology and Microbiology, Karnatak University Dharwad, India for providing basic lab facilities for doing research work and I thank Dr Murigendra Hiremath and his $\mathrm{PhD}$ students for providing me Laboratory for doing the work.Thankful to research scholar Sheetal Kesti for helping in identification of termite species and would like to thank CYTXON BioSolutions Pvt. Ltd, for helping in molecular characterization of isolated gut microorganisms.

\section{REFERENCES}

[1]. Ohkuma, M, "Termite symbiotic systems: efficient bio-recycling of lignocellulose", Applied microbiology and biotechnology, Vol.61, Issue.1, pp.1-5, 2003.

[2]. Bugg, T. D, Ahmad, M, Hardiman, E. M, \& Singh, R, "The emerging role for bacteria in lignin degradation and bio-product formation". Current opinion in biotechnology, Vol.22, Issue.3, pp.394-400, 2011.

[3]. McDonald, J. E, Rooks, D. J, \& McCarthy, A. J, "Methods for the isolation of cellulose-degrading microorganisms". In Methods in enzymology, Vol.510, pp. 349-374). Academic Press,2012.

[4]. Brune, A, "Symbiotic digestion of lignocellulose in termite guts". Nature Reviews Microbiology, Vol.12, Issue.3, pp168, 2014.

[5]. Scharf, M. E, "Omic research in termites: an overview and a roadmap". Frontiers in genetics, Vol.6, pp.76, 2015.

[6]. Fraune, S, \& Bosch, T. C. "Why bacteria matter in animal development and evolution". Bioessays, Vol.32, Issue.7, pp.571$580,2010$.

[7]. Scharf, M. E. "Termites as targets and models for biotechnology". Annual review of entomology, Vol.60, pp.77-102, 2015.

[8]. Warnecke, F, Luginbühl, P, Ivanova, N, Ghassemian, M., Richardson, T. H., Stege, J. T,\& Sorek, R. "Metagenomic and functional analysis of hindgut microbiota of a wood-feeding higher termite". Nature, Vol.450, Issue.7169, pp.560, 2007. 
[9]. Eggleton, P. “An introduction to termites: biology, taxonomy and functional morphology. In Biology of termites: a modern synthesis". Springer, Dordrecht, pp.1-26, 2010.

[10]. Upadhyaya, S. K, Manandhar, A, Mainali, H, Pokhrel, A. R, Rijal, A, Pradhan, B, \& Koirala, B. "Isolation and characterization of cellulolytic bacteria from gut of termite". In Rentech Symposium Compendium, Vol.1, Issue.4, pp.14-18, 2012.

[11]. Saitou, N, \& Nei, M. "The neighbor-joining method: a new method for reconstructing phylogenetic trees". Molecular biology and evolution, Vol.4, Issue.4, pp.406-425, 1987

[12]. Felsenstein, J. "Confidence limits on phylogenies: an approach using the bootstrap". Evolution, Vol.39, Issue.4, pp.783-791, 1985.

[13]. Kimura, M. "A simple method for estimating evolutionary rates of base substitutions through comparative studies of nucleotide sequences". Journal of molecular evolution, Vol.16, Issue.2, pp.111-120, 1980.

[14]. Tamura, K, Peterson, D, Peterson, N, Stecher, G, Nei, M, \& Kumar, S. "MEGA5: molecular evolutionary genetics analysis using maximum likelihood, evolutionary distance, and maximum parsimony methods". Molecular biology and evolution, Vol.28, Issue.10, pp.2731-2739, 2011.

[15]. Chou, J. H, Chen, W. M, Arun, A. B, \& Young, C. C. Trabulsiella odontotermitis sp. nov. "isolated from the gut of the termite Odontotermes formosanus Shiraki". International journal of systematic and evolutionary microbiology, Vol.57, Issue.4, pp.696-700, 2007.

[16]. Herzog, P., Winkler, I., Wolking, D., Kämpfer, P., \& Lipski, A. "Chryseobacterium ureilyticum sp. nov., Chryseobacterium gambrini sp. nov., Chryseobacterium pallidum sp. nov. and Chryseobacterium molle sp. nov., isolated from beer-bottling plants". International journal of systematic and evolutionary microbiology, Vol.58, Issue.1, pp26-33, 2008. 